\title{
VIÚVAS: \\ o mistério da ausência
}

\author{
Alda Britto da Motta* \\ "Estou insuportavelmente feliz!" \\ (recém-viúva, meia idade, confidenciando à vizinha. 2000).
}

\section{Resumo}

Trata de um estudo exploratório sobre a viuvez feminina na terceira idade. As viúvas sempre povoaram o imaginário cotidiano. Tradicionalmente vestidas de modo "diferente" e severo, de preto ou roxo, socialmente mais recolhidas, vivendo a ambivalência de terem e não terem o laço de casamento, apesar dessas peculiaridades e do seu peso demográfico significativo, são quase ausentes na produção científica, inclusive a de orientação feminista. No Brasil, entre alusões irônicas às "viúvas alegres", e pérfidas referências às "dores de viúva", a sociedade sempre esteve atenta às mulheres que poderiam "sair da linha" dos traçados normativos familiais - mesmo assim, são raros os estudos que se detêm nessa peculiar e desconcertante personagem "sobra de família". A modernidade ocidental multiplica-se com a longevidade da população, assumindo, crescentemente, papéis familiares e posturas sociais novas, que raramente são registrados na pesquisa científica. Discute a questão com base em estudos e pesquisas realizados pela autora sobre envelhecimento e relações de gênero, em Salvador, Bahia. Palavras-chave: Viuvez. Mulheres. Gênero. Envelhecimento.

\section{Introdução}

As viúvas sempre povoaram o imaginário cotidiano, mas não o dos cientistas sociais. Apesar do seu número demograficamente significativo, sempre estiveram praticamente ausentes dos estudos e pesquisas científicas. Ausentes, sobretudo porque a condição de viuvez é majoritariamente das

\footnotetext{
* Professora da Pós-Graduação em Ciências Sociais e Pesquisadora do Núcleo de Estudos Interdisciplinares sobre a Mulher (NEIM) / Universidade Federal da Bahia (UFBa). E-mail: aldamotta01@hotmail.com
} 
mulheres, e identificada, como estereótipo, basicamente a estas - e as mulheres sempre foram um menos importante "segundo sexo" (BEAUVOIR, 1990).

Entretanto, ou por isso mesmo, entre alusões críticas às possíveis "viúvas alegres" e à pérfida "dor de viúva", especialização matreira das "dores de cotovelo", a sociedade sempre esteve atenta para cobranças às mulheres que, uma vez sozinhas - isto é, fora da companhia ou do alcance do poder masculino - "saíssem da linha" dos estreitos traçados normativos da moral familial.

Assim posta a questão, pode parecer que me reporto ao passado nada longínquo, evidentemente - ao tempo dos lutos "fechados", das roupas negras, véus e recolhimento, do luto que só depois de muitos meses - ou nunca-seria "aliviado", simbolicamente representado no cinza, de meados do século XX. Sim, mas falo também do tempo presente, onde aquela peculiar personagem "sobra de família" vive e atua num crescendo, multiplicando-se rapidamente com o envelhecimento e o aumento de longevidade da população (também com a violência atual, que inaugurou a categoria viúva adolescente), assumindo novos papéis familiais e postura sociais; mas que ainda assim raramente é objeto de registro direto (ou específico) na pesquisa científica, onde as viúvas comparecem diluídas nos estudos gerais sobre a mulher, ou principalmente sobre família, emergindo daí como circunscritas avós. Mas ainda é personagem que, pouco exposta, mantém algo da sua tradicional fantasmagoria, "assombrando", de quando em quando, com inesperadas aparições.

Em Carnaval recente (2002), por exemplo, jornais do país estamparam, com destaque, a foto de um homem fantasiado... de viúva! Levando mais longe o velho deleite masculino em caracterizar-se como esse "bicho esquisito" que seria a mulher, apresenta-se como um ser ainda mais "estranho", a viúva: vestido escuro, luvas pretas, longas, mas que deixam as mãos de fora; chapéu de abas largas, completamente cobertas por bolas pretas (o nome do clube que desfilava, no Rio de Janeiro), colares, pulseiras, brinco e leque aberto. A que estranha fantasia mental corresponderá a fantasia material, vestida e enchapelada... por um homem?! 
Neste trabalho, analiso, exploratoriamente, uma personagem paradigmática do drama familial: a viúva de mais idade. Basear-me-ei em observações e elementos de entrevistas realizadas com idosos em minhas pesquisas mais recentes. ${ }^{1}$

\section{Ser Viúva}

A viuvez é uma condição social peculiar: inesperada, não planejada, instantaneamente modificadora da vida das pessoas. Representa uma súbita quebra do equilíbrio, real ou suposto, das relações de família e a urgência do estabelecimento de novos arranjos no grupo familial. Em sociedades menos complexas figura uma espécie de rompimento involuntário do dispositivo da aliança, mas ao mesmo tempo ocorrido, em grande parte das vezes, para as mulheres, em um período já não-reprodutivo. Entretanto, onde a mulher tem sido subordinada a partir das regulações primeiras da sua capacidade reprodutiva, é na viuvez e na velhice que alcança uma posição mais livre e mais pública, por vezes equivalente à dos homens (MEILLASSOUX, 1977).

Na modernidade capitalista, onde a família nuclear se constituiu também como modelo ideológico (MOTTA, 1998a), a figura da viúva deixa essa representação "perdida". Para os grupos e para a própria pessoa. Afetividades inesperadas, solidariedades e até conflitos, novos, geracionais e de gênero, são desencadeados, enquanto o grupo não redesenha as novas ligações e circuitos relacionais. Durkheim (1982, p. 205-206) chega a cunhar, para essa circunstância, o termo "anomia doméstica", "[... ] uma desorganização total da família cuja influência o cônjuge sobrevivente sofre.” Preocupa-se, avalia que o viúvo sofre mais do que a viúva, baseado em sua estranha teoria de que o casamento é menos benéfico às mulheres que aos homens, porque aquelas são menos impregnadas de sociabilidade que estes.

Essa idéia de ruptura do par e incompletude pessoal e social atravessa os tempos. O casal é uma força que urge preservar, embora, em certas circunstâncias das relações de gênero, seja também uma força que pode manietar e de que é positivo se liberar (veja-se a epígrafe).

Em estudo pioneiro sobre avós, Lins de Barros (1987) dá pistas sobre a alternativa de afirmação do casal: a entrevistada Ida, viúva de 72

A que originou a Tese (1999) e o projeto "Os Velhos mais Velhos" (CNPQ e PIBIC/UFBA, 2002), no qual participaram, os estudantes: Patrícia Schramm Andrade, Carla Pellegrino, Ulisses Amorim, Fabiana Negreiros de Santana e Zilmar Alverita da Silva. 
anos, afirma que "Ser avó com marido é uma coisa, sem marido é outra." (p. 71). Comentando a autora, em momento posterior: " [... ] sua própria situação de viúva a fragiliza." (p. 127). Inclusive pelo temor da comum “[ . . . ] invasão por parte dos filhos e a conseqüente perda de independência dos velhos pais, quando enviuvam.” (p. 127). Por fim, analisa como “[ . . . ] a falta do par conjugal é vista como uma fragilidade...” (p. 127) também pela família, em outras circunstâncias do seu ciclo de vida.

Enquanto um novo percurso não se traça, a viúva tem sido também uma espécie de "inau", como relata Simone de Beauvoir (1990, p. 66) sobre os hotentotes: alguém que interrompeu um ciclo, "[ . . . ] encontra-se numa situação de transição, não pertence mais a nenhum grupo, está em perigo e é perigoso." Não são raros os depoimentos de viúvas mais jovens, assim como de descasadas, sobre os "perigos" que lhes atribuíam outras famílias: esposas, por medo de competição; maridos, por medo dos "maus exemplos". Aliás, o aumento dos casos de separação contribuiu significativamente para atenuar a carga de vigilância, assédio e até "mistério" posta sobre as viúvas.

Mas, enquanto o novo ciclo de vida pessoal e de família se refaz, são muitas as mudanças que se processam. E não apenas aquelas, imediatas, relativas à posição e participação no grupo familial, inclusive o ampliado; e aí também posta a família de origem do falecido. Há mudanças, ainda, por extensão, em outros âmbitos grupais, por força do fato concreto de ter a mulher deixado de ser esposa, membro daquela díade especial e tranquilizadora, o casal casado. Há, subitamente, uma personagem faltando nesse drama e, principalmente no caso da mulher idosa e de camadas sociais mais altas, falta o provedor, chefe do grupo doméstico e seu representante na esfera pública. Inclusive, elo no grupo de amigos.

D. Marieta, viúva de 81 anos, demonstra, a exemplo de outras mulheres de classe média, as dificuldades de uma geração que era preparada apenas para a vida privada, quando subitamente se encontravam sós e tinham que atuar no espaço público: "Quando a gente é muito dependente do marido, não é muito fácil, não. É o meu caso. A falta é grande. Eu sem ter hábito de nada, pela minha criação, vivia no meio de minha família e depois que me casei continuei no mesmo ritmo. Não tinha outro movimento a não ser o de mãe de família."

Helena Lopata (1970, p. 52), um dos raríssimos autores que vem se dedicando ao tema da viuvez - e até se especializando nele (1996) -, enfatiza esse aspecto da perda, embora com certo exagero funcionalista e 
gerontológico sobre trocas de papéis e o conseqüente desengajamento. Mas vai até as viúvas, diretamente, entrevistando e revendo as relações sociais desenvolvidas - ou não mais - depois da viuvez, em uma cidade de grande porte (Chicago), nos Estados Unidos. Aponta dificuldades. Por exemplo, tentar manter amizade e companheirismo com os casais freqüentados no tempo do marido vivo, levando-as a sentir-se "like a fifth wheel." Ao mesmo tempo que a participação em um grupo de viúvas era sentido como perda de status e também perda de uma apreciada companhia masculina.

Lopata (1970, p. 55) considera, de forma equivocada, uma alternativa difícil essas mulheres fazerem amizades, por "[ ... ] falha do processo de socialização [... ]." Trata-se, entretanto, de um trabalho mais antigo, que embora documente muitas das dificuldades vividas pelas viúvas - e não apenas americanas - na época, talvez não pudesse antever situações encontradas comumente apenas dez ou quinze anos depois, como os novos grupos, típicos das décadas de 80 e 90 , propostos/organizados para a "terceira idade". Isto é, para os idosos mais jovens, e que rapidamente se generalizaram - sem necessidade de maiores preparos socializadores individuais, apenas afinados com os acontecimentos do tempo social - e contribuem, ainda hoje e cada vez mais, para a reinserção social, ainda que um tanto guetificante, em termos geracionais, desses idosos, que é inédita. ${ }^{2}$

Aliás, é importante lembrar-se que, ainda anteriormente à eclosão social desses grupos, situações diferenciadas de classe já ensejavam, evidentemente, outras formas de viver a viuvez. A experiência, há alguns anos atrás, de D. Ana, empregada doméstica e depois pensionista, ao contrário de D. Marieta, foi de autonomia: "Dez anos que eu estou sem ele, mas não faz diferença nenhuma, porque eu já labutava minha vida sozinha. Tinha ele, mas pra mim era indiferente, eu trabalhava."

Evidencia-se, então, como a aparente universalidade da situação de viuvez, originada, em toda parte, do mesmo fato fundador, a morte do cônjuge, é, ao mesmo tempo, vivenciada de forma diferenciada segundo a situação de classe e de gênero - entre outras inserções sociais - dos indivíduos.

A viuvez guarda, realmente, um forte e especial significado de gênero - não só porque o contrato social fundador da relação perdida (?), o casamento, emana de situações estabelecidas nessa dimensão da vida social,

2 Sobre esses grupos e seus significados, ver Motta (1997a, 1997b, 1999); Cabral (1997, 2002); Peixoto (1995, 1997a); Gomes (2001). 
mas também porque o fato cultural viuvez é diferentemente vivido e representado segundo se trate de homens ou de mulheres.

Para os homens é fenômeno demográfico de incidência baixa, mesmo entre os mais velhos. Quando ocorre, concomitante aos choques afetivo e representacional, o cotidiano transcorre entre a desvalia ("helplessness") doméstica e o recurso aos saberes e ajudas de outras mulheres disponíveis, geralmente do próprio círculo familiar. Com meios próprios de subsistência, a ajuda necessária é somente "técnica" - quanto à casa e filhos, quando estes existem. Em maioria recasam, sem grande demora, quase sempre com mulheres mais jovens do que a esposa anterior. ${ }^{3}$

Paraas mulheres, a viuvezé, em toda parte, uma questão avassaladoramente de gênero. E por ser uma questão demográfica e culturalmente feminina, a viuvez tem sido objeto de preocupação/vigilância popular, ao mesmo tempo em que ignorada pelas ciências sociais, tradicionalmente androcêntricas.

Aliás, a categoria/personagem viúva tem sido negligenciada até pela literatura feminista, que, sabe-se, não costuma ocupar-se das mulheres de mais idade (MOTTA, 2000), nem de situações onde as relações de poder são menos imediatas ou menos visíveis - as que se dão entre as gerações.

Em resumo, no âmbito social extra-cotidiano, a personagem viúva, por ser mulher e sobrevivente de uma relação interrompida, figura como desimportante. Em maioria não-jovem, de atuação principalmente privada/ doméstica, só aparece socialmente se prevaricar, ou, no outro extremo, constituir-se em modelo ímpar de "virtudes" popularmente referenciadas à sexualidade. Por isso, D. Lili, vigorosa senhora de 86 anos e viúva há várias décadas, declarou-me - a exemplo de outras entrevistadas - com certo orgulho: "Aqui tem uma criatura (vizinha) que diz que sou um exemplo: não quis saber de casamento, procedi bem, criei meus filhos com meu trabalho." (grifo nosso).

Bem, este é um modelo comportamental que vai se esfumando no tempo, embora mantenha uma persistente atualidade entre os mais velhos. Porém mesmo entre estes delineiam-se modelos mais novos de atuação, de crescente vigência, das viúvas mais ativas e livres, do pós-feminismo e do interregno brilhante das conquistas previdenciárias, já fadadas ao achatamento e desaparecimento.

\footnotetext{
3 No total das duas referidas pesquisas, só encontrei seis (6) viúvos, dois (2) dos quais faleceram durante o trabalho de campo.
} 
Duas matérias da Folha de São Paulo, em momentos diferentes, são ilustrativas dessa mudança. A primeira, em 1997, sobre uma possível solidão feminina, documenta bem mais claramente o sentimento das viúvas "aliviadas" sem negativismo, expressando ao mesmo tempo o modo tradicional de aprisionamento cultural e as possibilidades de um novo modo de ser velha e viúva. O caso da Sra. Eleonor Paris, 70 anos:

Eu era muito presa. Não podia fazer nada que eu queria. Desde que meu marido morreu, moro sozinha no meu cantinho. Como meus três filhos já estavam grandes, comecei a fazer tudo que tinha vontade. Não sei o que é solidão, porque tento ter uma vida social muito ativa. Eu posso me considerar hoje uma pessoa feliz. Não que eu não fosse feliz com meu marido. Mas a maneira que eu levo minha vida hoje é muito melhor. (MULHERES..., 1997, p. 1).

A propósito de longevidade e viuvez, é ouvida, no Rio de Janeiro, Maria das Neves Luna Freire, 79 anos, o outro caso modelar:

Sou viúva há 27 anos. Depois que o meu marido morreu, tive que aprender a me virar, diz Maria das Neves, rindo. Ela conta que, depois de ficar viúva, começou a procurar emprego. Trabalhou como professora, como recreadora $\mathrm{e}$ atualmente é secretária num consultório médico. Gasta parte do salário para comprar vestidos e ir dançar nos bailes com outras amigas. Nélia se define como 'uma viúva alegre' e conta que procura levar uma vida saudável para viver, pelo menos, mais 20 anos. Caminho todos os dias na praia, tomo sol, faço hidroginástica e freqüento um centro espírita para cuidar da alma. Como é 'do tempo em que mulher não trabalhava', ela hoje vive da pensão do marido. (ROSALINA..., 2001, p. 1).

Esses e outros registros que vão aparecendo na mídia, na televisiva também, assinalam tanto essa mudança, em curso, dos modos tradicionais de viver a viuvez e a velhice, como também - nem que seja pelo ineditismo da situação - como o fato de que estão começando a interessar à sociedade. É, portanto, o momento em que muitas das críticas e receios de autores como Betty Potash (1986), outra das raras pioneiras em estudos sobre viuvez, 
podem começar a aquietar. Principalmente quanto à situação periférica das viúvas: "As sociedades ocidentais, que são estruturadas através do casamento... enfatizam a união do companheirismo e os fundos conjugais comuns." (POTASH, 1986, p. 3). Porque elas hoje, na sociedade do desemprego estrutural e da precariedade do trabalho, são freqüentes esteios familiais, com suas pensões e aposentadorias (MOTTA, 1998a). Críticas de Potash (1986, p. 43) quase superadas, também, quanto ao fato de que "[ . . . ] não se ouve as viúvas."

A propósito, vejamos como estão as velhas viúvas baianas.

\section{Experiências de Viuvez}

A aproximação direta, no processo de pesquisa, com viúvas e alguns raros viúvos, se deu, como referido, durante o desenvolvimento de dois projetos. O primeiro, "Vivendo e Aprendendo", com idosos "jovens", em maioria, que se reúnem em grupos para a "terceira idade" - trabalho de que resultou minha tese de doutorado (MOTTA, 1999). Foram 28 viúvas entrevistadas, em três diferentes grupos, mas sem questões postas diretamente sobre o tema. Ainda assim, colhi alguns depoimentos expressivos.

O segundo projeto, "Os Velhos mais Velhos", finalizado em 2002, estuda os modos de vida de uma "quarta idade", menos dinâmica, encontrados direta e individualmente em casa, sem freqüência àqueles alegres grupos "de terceira idade". São 32 viúvas, entrevistadas em duas etapas de trabalho de campo, já com algumas questões postas diretamente sobre viuvez.

O primeiro registro feito seria sobre a heterogeneidade da categoria e da vivência de viuvez. Mas não apenas pela conhecida e já mencionada diferenciação segundo o gênero, ou a classe social, esta sempre inescapável, além das naturais variações de ordem subjetiva, pessoal. Uma heterogeneidade que se evidencia mais recentemente e merece registro é a da situação/vivência no tempo social, que se expressa nos modos de vida de diferentes gerações - na minha pesquisa, gerações de idosos.

Vivendo a viuvez, essas duas "populações", a partir de diferentes momentos cronológicos-sociais em fins do século XX, com diferentes idades (entre 60 e mais de 100 anos), segundo "habitus" (BOURDIEU, 1990) também formados segundo a geração, em parte vivem diferenciadamente $\mathrm{o}$

\footnotetext{
${ }^{4}$ No original: "Western societies, which are conjugally structured... emphasize companionate marriage and common conjugal funds."
} 
período 1997-2002: uma certa não contemporaneidade de contemporâneos, como definiria Mannheim [19-]. Ao mesmo tempo, compartilham características homogeneizadoras básicas, nesse jogo do tempo, de que são principais condições a viuvez e a velhice. Que por seu turno são representadas e vividas de modo diferenciado, como estamos vendo.

A viuvez é também uma condição, pelo menos inicialmente, ambígua e ambivalente - ambigüidade de sentimentos, ambivalência de situação, principalmente para a mulher: não estar mais, e de certo modo ainda estar casada. Situação magnificamente representada pela tradicional-em processo de desuso - prescrição de seguir carregando a aliança do morto. Em tempos não muito pretéritos, ser a "Viúva Fulano de Tal", ainda sem um nome social próprio. Distintivo de classe, aliás, não de todo abandonado, como ainda se encontra em nomes de tradicionais casas comerciais, em Salvador, a exemplo da conhecida Óptica Viúva Neves, e, eventualmente, em notícias fúnebres nos jornais, como ilustra o Convite a seguir, que me trouxe, ao primeiro impacto, a reação: "Sem individualidade até na morte!" E me fez lembrar Meillassoux (1977, p. 128): “As mulheres não morrem, desaparecem.” E pensar ainda: também pode ser assim em sociedades complexas.

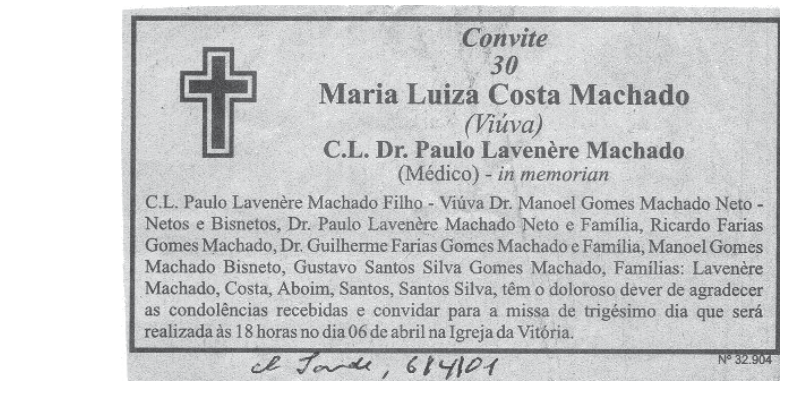

FIGURA - Convite

Fonte: CONVITE N ${ }^{\circ}$ 32.904. A Tarde, Salvador, 6. abr. 2001. Caderno 1, p. 6 .

Entre as muito idosas, da minha pesquisa, essa ambigüidade, essas relações de não-ser-sendo, foram encontradas, até em algumas referências, ou invocações, ao "namorado" ou "marido" "que me espera lá no céu." $\mathrm{Ou}$ em revelações de que haviam jurado ao agora falecido que jamais iriam ter outro homem.

Na pesquisa, em um dos grupos de idosos “jovens" de classe média e bom nível de instrução, algo dessa ambigüidade foi externado, em outro 
diapasão, tom mais leve, até em modos de expressão jocosos, como na entrevista daquela que declarou que viuvez é "A pior coisa que existe", porém entre risos. Igualmente curioso foi o teor das declarações que foram se sucedendo: "Tranqüilo, é do ciclo da vida." "Sem dramas ou problemas" (acrescentando que só agora se diverte). "Não é das piores coisas." Até celebrar: "Foi muito bom." A única expressão de negatividade foi encontrada na que nunca trabalhara e, sozinha com filhos pequenos, sem experiência, foi trabalhar pela primeira vez.

Já naquela ocasião (MOTTA, 1999) comentei como as revelações desse tipo de dificuldade, tanto quanto as de contentamento pela viuvez, não chegavam a surpreender, dadas as peculiaridades do casamento tradicional na sociedade capitalista e as relações de poder, com subordinação explícita da mulher, construídas ou continuadas nele. Não seria de admirar-se, então, que mesmo situações que se iniciaram como amorosas fossem transformandose, naquele clima e na vivência e desgaste cotidianos, em desconfortáveis ou até sofridas, a ponto de seu término produzir algum alívio.

Os depoimentos se sucederam, nesse diapasão:

"Pra mim foi muito bom, porque eu não fui feliz no casamento. Gostei e não vou mentir." (75 anos, viúva há 40 anos).

"Marido Don Juan... Não tive dramas, problemas. Agora eu deveria administrar a casa. A filha única casada, não tinha problemas com quem dar comida." [arrolou várias atividades e distrações que, afinal, conseguiu ter, arrematando:] "Ele não me permitia divertir." (61 anos, 15 de viúva).

Uma viúva mais recente, 68 anos, apenas declara: "Tem horas que a gente se sente muito só, mas agora me sinto mais solta. Em dois anos de viuvez já fiz duas viagens ao Exterior. Coisas que eu não podia fazer antes."

Não se referiu à vida de casada, como várias outras. Mas coincide que conheço sua família e sempre soube de atitudes de dominação ciumenta e meio violenta, por parte do marido, que a levavam ao desespero. O que nunca foi referido na entrevista, que ela espontaneamente procurou.

Nos dois grupos de viúvas “jovens", de classes populares, as maiores revelações sobre o seu estado atual vieram quando de pergunta/teste, se 
gostariam de casar de novo. Apesar do casamento ter estado como um dos projetos de vida da maioria delas, todas repeliram, em variados graus de veemência, a idéia de retomada de uma convivência desse tipo. Apenas duas condicionaram: Se fosse com o mesmo marido, que era muito bom.

As recusas tiveram formas de expressão muito semelhantes, o que as situa como decorrência provável da subordinação de gênero agravada pela situação de pobreza, como está expressa ao longo da quase totalidade das entrevistas: casamento cedo, não estudar, não ter permissão para trabalhar, poucos passeios, nada de festas... (MOTTA, 1999). Passados os nada incomumente difíceis primeiros tempos de viuvez, as reações agora são de recusa a nova experiência:

"Deus me livre! Não quero mais. Eu vejo o espelho dos outros. As pessoas estão viúvas e vivendo numa boa, aí casam de novo para arranjar problemas!" (64 anos).

"Ave Maria! Eu não gostaria de casar de novo, de ter marido! Estou bem assim." (68 anos).

"Acho que ia ser pior do que foi. Deus me livre! Não quero nem pensar." (60 anos).

"Eu não gostaria de casar de novo, para não ficar embaixo do pé de homem. Não me acostumo ninguém mais mandando em mim. Eu sozinha estou melhor." (60 anos).

"Já tem vinte anos que eu sou viúva e nunca mais arranjei ninguém. Também eu não quero ficar em casa lavando roupa de homem velho, enquanto eles vão pra rua arranjar outras." (66 anos).

"Não gostaria mais, de jeito nenhum. Agora que estou sozinha, vou pra onde quero: quando era casada não tinha liberdade." (68 anos).

Boa parte delas admitiria a possibilidade, ou o sonho, de namorar, "curtir", "se divertir junto", mas nunca de casar de novo.

É uma geração ainda "jovem", diante da longevidade atual: "passando a vida a limpo", afirmando que "chegou o tempo de pensar também em mim", 
e não exclusivamente na família, podendo aspirar a uma liberdade que suas mães nem pensariam - uma comparação que sempre fazem - podendo aproveitar o tempo para vivenciar os novos modos de ser velho (MOTTA, 1998a). Um tempo, então, em que a sociedade se direcionou no sentido de "aliviar" o luto das viúvas e, portanto, facultar a que elas sintam-se literalmente mais leves, e livres. ${ }^{5}$

Entre as mais velhas, na pesquisa com idades até 102 anos, ao contrário das minhas expectativas são raras as que contam histórias, ou sequer se reportam aos primeiros anos de viuvez - perdidos no tempo ou em interesse, talvez - o fato é que, de forma bastante generalizada, fazem relatos sumários dessa trajetória, ou nenhum. Tempos "difíceis", "horríveis", ou "de alívio", “mudando para melhor.' Essa desmemória está extremada em D. Valdomira, 83 anos e 18 de viuvez, que no decurso da entrevista revela que nem se dera conta de que já havia tanto tempo passado desde a morte do marido. Mora em uma casa que "[ . . . ] construi sem ajuda", com uma das filhas e uma neta "abusada", a quem deseja um casamento rápido... para livrar-se dela. Ao final, diante da questão "como é ser viúva?", apenas recuperou:

"É ter a lembrança de quem já se foi... Nunca me esqueço dele! Mas nada mudou, não, continuo alegre como sempre fui."

Desmentindo o estereótipo de que os velhos vivem do (e no) passado, fincaram-se no presente, essas viúvas; e em dois pontos principais de referência ou definições do seu cotidiano:

a) passaram a ter aquela experiência apreciadíssima de liberdade e a se divertir: passeios, festas, danças, novas amizades, até namoro - são, principalmente, as idosas "jovens", até os setenta e poucos anos;

b) vivem, hoje, "muito bem", entre carinhos e cuidados, com os filhos sempre as mais velhas. Refazem o "ninho", parece. Algumas destas gostam ou precisam morar sozinhas, inclusive, três moram em asilo, mas a referência central de vida é, ainda quando negativa (caso dessas três), à família.

Poderia, talvez, sumariar essas situações/referências a partir de outro ângulo: ter "saído de casa", ou da família como fonte única das suas relações

\footnotetext{
5 Ao longo de vários textos, venho trabalhando a categoria liberdade, aplicada principalmente a essa fase da vida dos idosos na contemporaneidade, em suas variantes "liberdade de gênero" e "liberdade geracional" (ver, por exemplo, 1997a e 1998b).
} 
sociais, para o cenário público de sociabilidade geracional e liberdade de movimento nunca antes experimentadas (MOTTA, 1999). Ou, alternativamente, ter reforçado uma construção de núcleo familiar satisfatória, e idealizada, de mães e filhos, podendo incluir outras gerações, onde as idosas ocupariam uma posição que julgam central, com declarações não raras do tipo "eu sou a matriarca", ou "são tão ligados em mim, que eu não sei como vai ser quando eu morrer!". Ao mesmo tempo, em alguns momentos deixando escapar, alternativa ou contraditoriamente, vezes com humor, outras como desabafo, a existência de certas trocas de papéis:

"Agora eu sou a filha..." (83 anos).

"O chefe da famillia hoje é meu filho, que mora aqui comigo." (84 anos).

"Eu me considero a chefe da família, mas hoje quem comanda tudo é minha filha Leonor." (77 anos).

Há, naturalmente, referências a perdas sentidas, de bons maridos "fomos felizes" - e até lacônicos "é horrível ser viúva", mas este não é o tom predominante. Por outro lado, alguns relatos chocam um pouco pela enorme naturalidade ou até distanciamento diante da perda (ou não houve grande perda...?) e até pela crueza de expressão, como estas, de pessoas de vários segmentos sociais (selecionadas para a pesquisa por um critério de idade):

"Eu fiquei sem ele... e foi o jeito. Eu dei graças a Deus que indenizaram e eu comprei essa casinha aqui e eu entrei pra dentro." (96 anos).

"Ele morreu e eu enterrei. Me deixou uma casa para morar, não sabe? Graças a Deus vivo muito folgada. Muito bem, porque tenho meus filhos. Tenho muita saudade dele, mas o que é que eu vou fazer?" (100 anos).

"No início o marido me fez muita falta: depois fui acostumando. Hoje não me faz falta nenhuma, vivo bem com meus filhos, eles me ajudam em tudo." (76 anos).

"Ele me maltratou muito, por isso, pra mim foi um alivio quando fiquei viúva. Não pense que queria que ele morresse, não, mas realmente foi como se de repente pudesse ter a liberdade que nunca tive." (87 anos). 
Ora, repare-se que as alternativas de reação à viuvez, antes de tudo à ausência do marido, são subjetivamente semelhantes, entre as mulheres dos dois grupos de idade, o tipo de resposta variando de acordo com as relações que antes haviam constituído. A diferença flagrante entre elas referese aos modos de vida de cada uma hoje, isto é, às possibilidades objetivas ensejadas pelo meio social a cada situação de idade/geração. É aquele caso do serem contemporâneas, mas com vivências e respostas ou soluções diferentes ao mesmo acontecimento.

Refletindo sobre o "aninhamento" dos mais velhos, reencontro um antes analisado (MOTTA, 1998a) protecionismo imobilizador por parte dos filhos (às vezes também de netos) sobre os "meus velhos". Para uns, fruto de afetividade pura, mas que se estende em cuidados por vezes exagerados e, portanto, ao final, cerceadores. Também alternativas nada raras de exploração dos recursos dos velhos, principalmente das velhas viúvas: morar juntos ou "cuidado" ou "preocupação com a saúde" destas, freqüentemente significando o governo da casa e da aposentadoria ou pensão que a viúva tem.

Peixoto (1997b, p. 150) também encontrou essa situação de modo muito nítido em relação ao uso da casa, estendido em ingerência sobre a vida privada das idosas:

[... ] são os filhos quem decidem sobre o destino da mãe, principalmente quando ela é proprietária do imóvel onde mora. Das duas uma: ou ela vai morar em casa do filho(a), liberando o imóvel para venda ou aluguel e os filhos se beneficiam do produto da negociação, ou um dos filhos vem morar com ela, deixando de pagar aluguel.

Este é também um ponto fundamental de diferença entre as idosas mais jovens e as velhas/velhas. Menos escolarizadas e informadas, com um passado de acesso restrito (principalmente ditado pela família) ao mercado de trabalho, fisicamente mais frágeis, as muito velhas, contentes, conformadas ou desanimadas sofrem uma espécie de asfixia afetiva dos filhos e netos, que lhes retira a possibilidade de acesso a uma liberdade que não chegaram a conquistar, porque ainda não era possível "no seu tempo". Mas que se tornou viável no "tempo" das mais jovens. 


\title{
4 Conclusões Provisórias
}

A escassez de estudos sobre viuvez trouxe um certo sentido de ineditismo e surpresa para mim, a cada achado na pesquisa. A viuvez nuançada não apenas pela condição de gênero, e pela de classe, mas também pela idade/geração, em velhices ao mesmo tempo comuns e diferentes. A alternativa entre desconsolo e inesperada frieza com que tem sido encarada a viuvez. $\mathrm{E}$ a "servidão voluntária" à família, das mais idosas.

Tentei traçar uma certa continuidade entre os tempos severos "de antigamente", de vigilância, malevolência e impedimentos às viúvas - social e economicamente - até uma atualidade de rápidas mudanças, em que, com a pós-revolução sexual, crescente inserção das mulheres no mercado de trabalho e eclosão social da figura da descasada, a pressão social se alivia, e um perfil ao mesmo tempo mais dinâmico e mais suave (conforme a geração das idosas) pode ser delineado, e se expressa nestes primeiros achados de campo sobre o tema.

A recomendação final seria, parafraseando Nelson Rodrigues sobre a alusão ao envelhecer (MOTTA, 1998b): Estudem as viúvas “" . . . ] antes que seja tarde". Inclusive, porque faço um estudo ainda exploratório; além de que permanecem quase intocadas, aguardando oportunidade de pesquisa, outras viuvezas: a dos homens de várias idades e a das mulheres muito jovens, criada pela violência urbana.

\section{WIDOWS: a misterious absence}

\begin{abstract}
This article is an exploratory study over the female widowhood in third age. Widows have always figured in everyday social imaginary. Traditionally wearing either black or purple and dressed in a severe fashion, facing social restrictions, and living the ambivalent situation of not having and at the same time still having - marriage links, they remain almost absent in scientific literature, including that of feminist orientation, despite their significant demographic weight. Brazilian society has always been attentive to women who could "step out of line" of the established norms, even if by means of
\end{abstract}


ironic allusions to "merry widows" and caustic references to "widow pains". Yet, studies focusing on this peculiar and ambivalent "family leftover" character are rare. But it should be registered that, in Western Modernity, widows not only are numerically multiplied as a result of population longevity, but also are assuming new familiar roles and social statuses, ignored, for the most part, as objects of interest or reference in scientific inquiry. In this paper, I discuss issues related to widowhood in Brazil, based on studies and research on ageing and gender relations carried out in Salvador, Bahia.

Keywords: Widows. Women. Gender. Ageing.

\section{REFERÊNCIAS}

BEAUVOIR, Simone de. A Velhice. Rio de Janeiro: Nova Fronteira, 1990. Edição original: 1970.

BOURDIEU, Pierre. Coisas Ditas. São Paulo: Brasiliense, 1990.

CABRAL, Benedita Edna de S. Lima. A Vida Começa todo Dia. Estudos Feministas, Rio de Janeiro, v. 5, n. 1, p. 159-168, 1997.

CABRAL, Benedita Edna de S. Lima. Recriar Laços: estudo sobre idosos e grupos de convivência nas classes populares paraibanas. 2002. Tese (Doutorado em Ciências Sociais) - Universidade Federal de Campinas, Campinas, 2002.

CONVITE No 32.904. A Tarde, Salvador, 6. abr. 2001. Caderno 1, p. 6.

DURKHEIM, Émile. O Suicídio. Rio: Zahar, 1982.

GOMES, Márcia Queiroz de Carvalho. Velhas e Velhos: a busca de novos espaços de sociabilidade. 2001. Dissertação (Mestrado em Ciências Sociais) - Programa de Pós-Graduação em Ciências Sociais, Universidade Federal da Bahia, Salvador, 2001.

LINS DE BARROS, Myriam Moraes. Autoridade e Afeto. Rio de Janeiro: Zahar, 1987. 
LOPATA, Helena Znaniecki. Current Widowhood: myths and realities (understanding families). Thousand Oaks, CA: Sage Publications, 1996.

LOPATA, Helena Znaniecki. The Social Involvement of American Widows. In: SHANAS, Ethel (Ed.). Aging in Contemporary Society. Beverly Hills: Sage Publications, 1970. p.40-56.

MANNHEIM, Karl. O Problema das Gerações. In: Sociologia do Conhecimento. Porto, Portugal: Res Editora, [19-]. P. 115-176. Publicação original em 1928.

MEILlASSOUX, Claude. Mulheres, Celeiros e Capitais. Lisboa: Afrontamento, 1977.

MOTTA, Alda Britto da. Terceira Idade: gênero, classe social e moda teórica. In: COSTA, Ana Alice Alcântara; ALVES, Ívia Iracema Duarte (Org.). Ritos, Mitos e Fatos. Salvador: NEIM/UFBA, 1997a. P. 103-120.

MOTTA, Alda Britto da. Palavras e Convivência: idosos, hoje. Estudos Feministas, Rio de Janeiro, v. 5, n.1, p. 129-139, 1997 b.

MOTTA, Alda Britto da. Reinventando Fases: a família do idoso. Caderno CRH, Salvador, n. 29, jul./dez. 1998a. Dossiê Gênero e Família, p. 13-21.

MOTTA, Alda Britto da. Chegando pra Idade. In: LINS DE BARROS, Myriam Moraes (Org.). Velhice ou Terceira Idade? (Estudos antropológicos sobre identidade, memória e política). Rio de Janeiro: Fundação Getúlio Vargas, 1998b. p. 223-235.

MOTTA, Alda Britto da. Não tá Morto quem Peleia. (A pedagogia inesperada nos grupos de idosos). 1999. Tese (Doutorado em Educação) Faculdade de Educação, Universidade Federal da Bahia, Salvador, 1999.

MOTTA, Alda Britto da. Geração a Diferença do Feminismo. In: SIMPÓSIO INTERNACIONAL O DESAFIO DA DIFERENÇA - ARTICULANDO GÊNERO, RAÇA E CLASSE, 1., 2000, Salvador. Anais... Salvador: UFBA/UEFS, 2000. 1 CD-ROM. 
MULHERES Envelhecem Sozinhas em São Paulo. Folha de São Paulo, São Paulo, p. 1, 22 jun. 1997.

PEIXOTO, Clarice Ehlers. A Sociabilidade dos Idosos Cariocas e Parisienses: a busca de estratégias para preencher o vazio da inatividade. Revista Brasileira de Ciências Sociais, São Paulo, n. 27, ano 10, p. 138-149, fev. 1995.

PEIXOTO, Clarice Ehlers. De Volta às Aulas ou como ser Estudante aos 60 anos. In: VERAS, Renato (Org.). Terceira Idade. Desafios para o terceiro milênio. Rio de Janeiro: Relume-Dumará/UnATI, 1997a. p. 41-75.

PEIXOTO, Clarice Ehlers. Histórias de Mais de 60 anos. Estudos Feministas, Rio de Janeiro, v. 5, n. 1, p. 148-158, 1997 b.

POTASH, Betty (Ed.). Widows in African Societies: choices and constraints. Stanford: Stanford University Press, 1986.

ROSALINA, 90, e Armando, 93, são o Único Casal da Turma. Folha de São Paulo, São Paulo, p. 1, 04 dez. 2001. 